\title{
Correction to: Human Interaction, Emerging Technologies and Future Applications III
}

Tareq Ahram, Redha Taiar, Karine Langlois, and Arnaud Choplin

\section{Correction to:}

T. Ahram et al. (Eds.): Human Interaction, Emerging Technologies and Future Applications III, AISC 1253, https://doi.org/10.1007/978-3-030-55307-4

In the original version of the chapter 28 , the name of the author was included erroneously. This has now been corrected as "Nasrine Olson".

In the original version of the chapter 79 , the abstract was included erroneously. This has now been corrected with the revised version.

The updated version of these chapters can be found at https://doi.org/10.1007/978-3-030-55307-4_28

https://doi.org/10.1007/978-3-030-55307-4_79

(C) The Editor(s) (if applicable) and The Author(s), under exclusive license

to Springer Nature Switzerland AG 2021

T. Ahram et al. (Eds.): IHIET 2020, AISC 1253, p. C1, 2021.

https://doi.org/10.1007/978-3-030-55307-4_96 